\title{
Tratamento do Carcinoma da Próstata Metastizado: Surgimento de Novos Horizontes Terapêuticos
}

Treatment of Metastasized Prostate Carcinoma: Emergence of New Therapeutic Horizons

Paulo Mota ${ }^{1,2}$, Nuno Morais ${ }^{1}$, João Pimentel Torres ${ }^{1,2}$, Agostinho Cordeiro ${ }^{1}$, Emanuel Dias ${ }^{1,2}$, Mário Cerqueira Alves ${ }^{1}$, Estevão Lima ${ }^{1,2}$

\section{RESUMO}

A evolução no tratamento do carcinoma da próstata metastizado proporciona atualmente ao Urologista uma vasta gama de possibilidades terapêuticas que comprovadamente melhoram a sobrevida e a qualidade de vida dos doentes. É apresentado um caso clínico neste artigo onde é patente não só a eficácia destas terapêuticas mas também a sua rápida evolução.

PALAVRAS-CHAVE: Antagonistas de Androgénios; Metástase Neoplásica; Neoplasias da Próstata/tratamento

\section{ABSTRACT}

The evolution in the treatment of metastatic prostate cancer currently provides to the urologist a wide range of therapeutic possibilities that have shown an improvement on overall survival and quality of life of patients. It is presented a clinical case in this article which reflects not only the effectiveness of these therapies but also their rapid evolution.

KEYWORDS: Androgen Antagonists; Neoplasm Metastasis; Prostatic Neoplasms/drug therapy

\section{INTRODUÇÃO}

O carcinoma da próstata metastiza e manifesta-se de diversas formas, implicando por isso diferentes formas de tratamento. A introdução recente de novos fármacos para tratar esta patologia veio abrir várias possibilidades de tratamento. ${ }^{1,2}$ De seguida é apresentado um caso clínico de um doente diagnosticado com cancro da próstata metastizado ab initio com o objetivo de evidenciar a melhor escolha terapêutica de acordo com a situação clínica.

1.Serviço de Urologia, Hospital de Braga, Braga, Portugal. 2.Instituto de Investigação de Ciências da Vida e da Saúde/Escola de Ciências da Saúde - Universidade do Minho, Braga, Portugal.

Recebido: 27/05/2016 - Aceite: 07/06/2016 

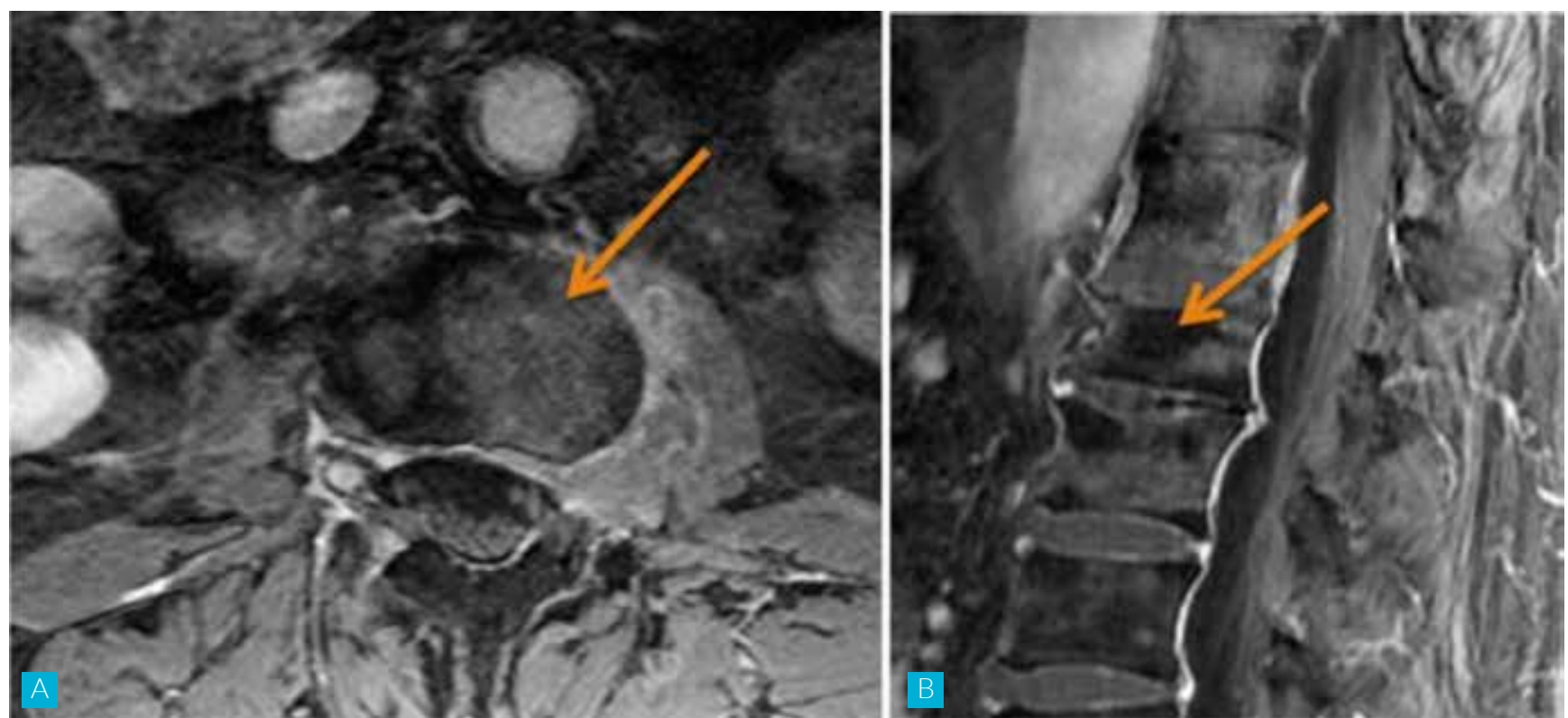

FIGURA 1. Imagens de ressonância magnética onde se visualizam metástases ósseas (setas amarelas).

Em A - cortes transversais. Em B - cortes sagitais.

\section{CASO CLÍNICO}

Homem de 74 anos, com antecedentes pessoais de doença cardíaca isquémica, com queixas de dor lombar com irradiação para o membro inferior direito, astenia e agravamento do estado geral com semanas de evolução. O toque retal revelou uma próstata de consistência endurecida. O estudo analítico solicitado revelou PSA $=32,56 \mathrm{ng} / \mathrm{mL}$. Foi realizada uma biópsia prostática trans-retal cuja histologia revelou a presença de adenocarcinoma da próstata Gleason 8 (4+4), em 9 de 11 fragmentos. A cintigrafia óssea revelou metástases na coluna cervical, lombar e bacia e a ressonância magnética da coluna vertebral mostrou que havia aparente compressão nervosa pelo processo metastático ósseo ao nível da coluna vertebral lombar (Fig. 1). O doente fez radioterapia da coluna vertebral e iniciou leuprorrelina (agonista LH-RH) e bicalutamida 150 mg (antagonista do recetor da testosterona), com melhoria rápida da dor lombar e redução do PSA (2,27 ng/mL após 3 meses). Passados 8 meses apresentou subida do PSA para 27,14 ng/mL (valores de testosterona total de $23 \mathrm{ng} / \mathrm{dL}$ ). Iniciou quimioterapia com docetaxel na dose de $75 \mathrm{mg} / \mathrm{m}^{2}$, sendo, no entanto, necessário efetuar a redução da dose de quimioterapia para 50\% devido a efeitos laterais marcados (fadiga e neutropenia). Após 6 ciclos de docetaxel o PSA encontrava-se em 10,71 ng/mL. Passados 4 meses, verificou-se progressivo agravamento do estado geral. Fez uma tomografia que evidenciou metastização pulmonar e adenomegalias retroperitoneais (Fig. 2A), com subida do PSA para 48,18 ng/mL. Foi iniciado o tratamento com abiraterona $1000 \mathrm{mg} / \mathrm{dia}$ + prednisona $10 \mathrm{mg} / \mathrm{dia}$ com excelente melhoria do estado geral, regressão imagio-

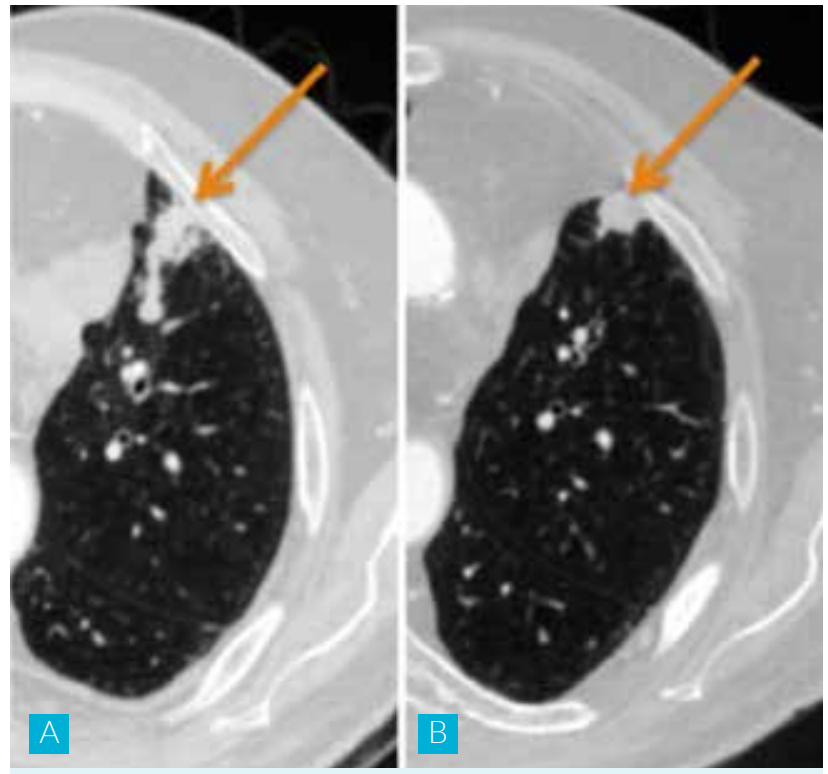

FIGURA 2. Imagens de tomografia computorizada onde se verifica uma redução do tamanho das lesões pulmonares de A para B (setas amarelas) após início de tratamento com um antagonista da testosterona de nova geração.

lógica das metástases pulmonares (Fig. 2B) e diminuição do valor de PSA para 8,17 ng/dL passados 7 meses (atualmente).

\section{DISCUSSÃO}

Da avaliação global deste caso clínico depreende-se que o adenocarcinoma da próstata é uma neoplasia para a qual existem atualmente várias modalidades terapêuticas que podem ser utilizadas de acordo com as manifestações clínicas, localização das metástases e características histológicas. 
Neste caso, a existência de metastização óssea na coluna vertebral com manifestações neurológicas associadas (compressão da espinal medula) tornaria desejável que o tratamento inicial fosse feito com um antagonista $\mathrm{LH}$ - RH ou com castração cirúrgica. ${ }^{1-3}$ Dada a indisponibilidade de degarelix optou-se por bloqueio hormonal completo com bons resultados. Não foi realizado tratamento inicial com docetaxel porque na altura este apenas estava indicado no cancro da próstata resistente à castração, diferente do que atualmente é recomendado.,2,4

Sendo o cancro da próstata uma doença de comportamento por vezes imprevisível queremos, neste caso clínico em concreto, realçar o excelente resultado da abiraterona na regressão imagiológica de metástases viscerais-pulmonares.

\section{CONCLUSÃO}

O surgimento de novas drogas, como os novos anti-androgénios, abriu portas terapêuticas onde antes existia o fim de linha e a mera paliação de sintomas.

CONFLITOS DE INTERESSES: Os autores declaram não ter qualquer conflito de interesses na realização do presente trabalho.

PROTEÇÃO DE PESSOAS E ANIMAIS: Os autores declaram que os procedimentos seguidos na elaboração do presente trabalho estão em conformidade com as normas das comissões de investigação clínica e de ética, bem como da declaração de Helsínquia e da Associação Médica Mundial.
FONTES DE FINANCIAMENTO: Não houve qualquer fonte de financiamento na realização do presente trabalho.

CONFIDENCIALIDADE DOS DADOS: Os autores declaram ter seguido os protocolos da sua instituição acerca da publicação de dados de doentes.

\section{REFERÊNCIAS}

1. Carroll PR, Parsons JK, Andriole G, Bahnson RR, Castle EP, Catalona WJ, et al. NCCN Guidelines Insights: Prostate Cancer Early Detection, Version 2.2016. J Natl Compr Canc Netw. 2016;14:509-19.

2. Mottet N, Bellmunt J, Briers E, Bolla M, Cornford P, De Santis $\mathrm{M}$, et al. EAU-ESTRO-SIOG Guidelines. Prostate Cancer. Update March 2016. [accessed March 2016] Available: http:// uroweb.org/wp-content/uploads/EAU-Guidelines-Prostate-Cancer-2016.pdf.

3. Roviello G, Sigala S, Sandhu S, Bonetta A, Cappelletti MR, Zanotti $L$, et al. Role of the novel generation of androgen receptor pathway targeted agents in the management of castration-resistant prostate cancer: A literature based meta-analysis of randomized trials. Eur J Cancer. 2016;61:111-21.

4. James ND, Sydes MR, Clarke NW, Mason MD, Dearnaley DP, Spears MR, et al. Addition of docetaxel, zoledronic acid, or both to first-line long-term hormone therapy in prostate cancer (STAMPEDE): survival results from an adaptive, multiarm, multistage, platform randomised controlled trial. Lancet. 2016;387:1163-77. 